\title{
A COMBINED ENRICHMENT/POLYMERASE CHAIN REACTION BASED METHOD FOR THE ROUTINE SCREENING OF STREPTOCOCCUS AGALACTIAE IN PREGNANT WOMEN
}

\author{
F.M. Munari ${ }^{1}$, F. De-Paris ${ }^{2}$, G.D. Salton ${ }^{1}$, P.S. Lora ${ }^{1}$, P. Giovanella ${ }^{1}$, A.B.M.P. Machado ${ }^{2}$, L.S. Laybauer ${ }^{2}$, K.R.P. Oliveira ${ }^{2}$, \\ C. Ferri ${ }^{3}$, J.L.S. Silveira ${ }^{4}$, C.C.F.C. Laurino ${ }^{1}$, R.M. Xavier ${ }^{1}$, A.L. Barth ${ }^{2}$, S. Echeverrigaray ${ }^{5}$, J.P. Laurino ${ }^{1,5^{*}}$
}

${ }^{1}$ Laboratório de Biologia Molecular em Doenças Auto-imunes e Infecciosas, Centro de Pesquisas, Hospital de Clínicas de Porto Alegre, Porto Alegre, RS, Brasil; ${ }^{2}$ Unidade de Microbiologia e Biologia Molecular, Serviço de Patologia Clínica, Hospital de Clínicas de Porto Alegre, Porto Alegre, RS, Brasil; ${ }^{3}$ Residente do Serviço de Pediatria do Hospital de Clínicas de Porto Alegre, Porto Alegre, RS, Brasil; ${ }^{4}$ Unidade de Terapia Intensiva Pediátrica da Santa Casa de Uruguaiana, Uruguaiana, RS, Brasil;

${ }^{5}$ Instituto de Biotecnologia, Universidade de Caxias do Sul, Caxias do Sul, RS, Brasil.

Submitted: October 14, 2010; Approved: January 16, 2012.

\begin{abstract}
Group B Streptococcus (GBS) is the most common cause of life-threatening infection in neonates. Guidelines from CDC recommend universal screening of pregnant women for rectovaginal GBS colonization. The objective of this study was to compare the performance of a combined enrichment/PCR based method targeting the atr gene in relation to culture using enrichment with selective broth medium (standard method) to identify the presence of GBS in pregnant women. Rectovaginal GBS samples from women at $\geq 36$ weeks of pregnancy were obtained with a swab and analyzed by the two methods. A total of 89 samples were evaluated. The prevalence of positive results for GBS detection was considerable higher when assessed by the combined enrichment/PCR method than with the standard method (35.9\% versus $22.5 \%$, respectively). The results demonstrated that the use of selective enrichment broth followed by PCR targeting the atr gene is a highly sensitive, specific and accurate test for GBS screening in pregnant women, allowing the detection of the bacteria even in lightly colonized patients. This PCR methodology may provide a useful diagnostic tool for GBS detection and contributes for a more accurate and effective intrapartum antibiotic and lower newborn mortality and morbidity.
\end{abstract}

Key words: Streptococcus agalactiae; Group B Streptococcus; atr gene; Screening test; Accuracy.

\section{INTRODUCTION}

Streptococcus agalactiae, also known as Group B Streptococcus (GBS), is associated to severe invasive disease in newborns. In fact, GBS is considered as one of the major causes of neonatal meningitis and sepsis (31).
It is estimated that 5 to $40 \%$ of all pregnant women may present rectovaginal colonization with GBS, most of which are asymptomatic (28) or associated with acute chorioamnionitis, endometritis, and urinary tract infection (32). Moreover, even just colonized or asymptomatic, pregnant women may transmit GBS to their newborns during labor and this may constitute

*Corresponding Author. Mailing address: Universidade de Caxias do Sul, Instituto de Biotecnologia, Rua Francisco Getúlio Vargas, 1130, Caxias do Sul, RS, Brasil CEP 95070-560.; Tel./Fax: +55 54 3218-2149.; E-mail: jlaurino@uol.com.br 
the first step for invasive disease in the first week of life (10).

The incidence of GBS neonatal infection was 1.4 per 1000 live births in USA in 1990 (10, 32, 40). Coinciding with active prevention efforts in the 1990s, the incidence of early-onset disease declined to 0.5 cases per 1,000 live births in 1999 (10, 24). In Brazil, few studies address early neonatal infection by GBS. The prevalence of GBS infection among neonates varied between 1.1 and 1.4 cases per 1,000 live births, in Porto Alegre (21) and Campinas (23), respectively. A recent study in a maternity hospital from Manaus (AM, Brazil) showed that the main microorganism isolated in blood cultures of newborns with early-onset sepsis was S. agalactiae (25).

Clinical syndromes of GBS disease in newborns include sepsis, meningitis, pneumonia, cellulitis, osteomyelitis, and septic arthritis. Bloodstream infections, with or without pneumonia, are the main manifestation of neonatal GBS disease and are observed in approximately $90 \%$ of cases, while meningitis occurs in around $10 \%(10,31)$. Other symptoms reported among older children include endocarditis $(2,34)$ and epiglottitis (38).

In addition to mother colonization, other maternal risk factors like preterm delivery, prolonged rupture of membranes ( $\geq 18$ hours), intrapartum temperature of at least $38^{\circ} \mathrm{C}$, or prior infant with GBS infection predispose a neonate to early-onset GBS contamination $(3,32)$.

Currently, the most effective strategy for reducing earlyonset GBS infection is prenatal maternal diagnosis of rectovaginal GBS colonization between the 35 th to 37 th weeks of gestation, followed by chemoprophylaxis $(3,10,37)$. The guidelines recommended by The Centers for Disease Control and Prevention (CDC) and The American College of Obstetricians and Gynecologists (ACOG) includes: (i) the sampling of the vaginal and anorectal regions with the aid of a swab which is submitted to bacteriological culture usually into selective broth medium (enrichment culture) followed by subculture onto sheep blood agar plates $(1,3,10)$, and (ii) the intrapartum chemoprophylaxis for those pregnant women with: positive maternal GBS screening, positive GBS urine culture during the current pregnancy, and a previous infant who had GBS infection (10). An oral chemoprophylaxis approach with antibiotics is not recommended because it is unlikely to eradicate maternal genital GBS colonization (13, 14, 29). However, although the laboratory methods for the identification of GBS have evolved, there remains a clinical need for greater accuracy, particularly in the case of asymptomatic colonization with low $\operatorname{GBS}$ charge $(4,15)$.

The aim of this study was to develop a highly sensitive and specific molecular method to evaluate GBS colonization in pregnant women. The proposed method combines a short enrichment culture followed by the amplification and detection of the atr gene with GBS specific primers.

\section{MATERIALS AND METHODS}

\section{Patients and samples}

The study was performed in 89 pregnant women $(\geq 36$ weeks of pregnancy) who attended the primary health care unit at an university hospital of Rio Grande do Sul State, Brazil, from April 2006 to May 2007. These 89 samples correspond to all medical requests for GBS search in the hospital service of obstetric primary care during this period.

Specimens of combined vaginal and anal secretions were collected using the technique recommended by the CDC (10), the STARD (9). Briefly, the vagina and the anus were sampled, and the swabs were immediately soaked into the Stuart's transport medium.

\section{Bacterial Enrichment Culture}

The swabs were transferred into $2 \mathrm{~mL}$ of $\mathrm{BHI}$ enrichment broth (BHI-E) supplemented with peptone $3(2 \mathrm{~g} / \mathrm{L})$, gentamicin $(8 \mu \mathrm{g} / \mathrm{mL})$ and nalidixic acid $(15 \mu \mathrm{g} / \mathrm{mL})$ to follow the microbiological identification as recommended by the CDC (10), and incubated at $36^{\circ} \mathrm{C}$ for $18-24$ hours.

\section{Microbiological method for the identification of GBS}

Enriched cultures were plated onto sheep blood agar plates 
(BioMérieux, Marcy L'Etoile, France), incubated at $36^{\circ} \mathrm{C}$ for 24 hours and inspected for characteristic GBS colonies. Whether these colonies were not identified, the plates were reincubated for another 24 hours and inspected again. When suspected colonies were present, they were subcultured in thioglycolate broth for 12 hours and then submitted to Gram stain. Colonies with Gram-positive cocci arranged in pairs and chains were submitted to CAMP test (Christie, Atkins, MunchPetersen). The specimens positive for the CAMP test were considered presumptive GBS (10).

\section{Identification of GBS by PCR Amplification}

The enriched cultures were centrifuged and the pellets were washed with PBS buffer, and then incubated with $500 \mu \mathrm{L}$ of $\mathrm{LiCl} 5 \mathrm{M}$ for 30 minutes at room temperature. DNAextraction was performed with the kit Wizard ${ }^{\circledR}$ Genomic DNA Purification (Promega corp, Madisson, WI, USA) according to the manufacturer's instructions. The purified DNA was resuspended to a final volume of $100 \mu \mathrm{L}$.

The PCR reactions were carried out using GBS specific primers $\operatorname{atrF}$ (5'-CGATTCTCTCAGCTTTGTTA-3') and atrR (5'-AAGAAATCTCTTGTGCGGAT-3'), that amplified a $779 \mathrm{bp}$ sequence of the atr gene, responsible for the glutamine transporter protein (gbs0538) of $S$. agalactiae. This housekeeping gene and the corresponding primers were selected from the $S$. agalactiae Multi Locus Sequence Typing (MLST) website - http://pubmlst.org/sagalactiae/ $(16,17,36)$.

PCR amplifications were performed in a total volume of $25 \mu$ containing: $0.2 \mathrm{mM}$ of dNTPs (ABgene ${ }^{\circledR}$, Epson, UK); $0.4 \mu \mathrm{M}$ of each atr-primer; 1x PCR buffer with $1.5 \mathrm{mM}$ of $\mathrm{MgCl}_{2}$ (JMR Holdings, London, UK); $1.0 \mathrm{U}$ of Super-Therm DNA polimerase (JMR Holdings, London, UK); $2 \mu \mathrm{L}$ of bacterial DNA (non-quantified). The amplifications were conducted on a MJ Research Thermocycler (Model PTC-100) with the following program: (i) $94^{\circ} \mathrm{C}$ for 1 minute, (ii) 30 cycles of 1 minute at $94^{\circ} \mathrm{C}, 45$ seconds at $55^{\circ} \mathrm{C}$, and 1 minute at $72^{\circ} \mathrm{C}$, and (iii) 10 minutes at $72^{\circ} \mathrm{C}$. Subsequently, $10 \mu \mathrm{L}$ of the amplified reaction were separated by electrophoresis in $2 \%$ agarose gels, and the amplicons visualized under UV light after ethidium bromide staining. The samples that exhibited a $779 \mathrm{bp}$ amplicon were considered positive for GBS. Purified GBS genomic DNA obtained from a clinical isolate was used as a positive control in all sets of PCR amplifications. This isolate came from a patient with neonatal sepsis and was properly characterized by microbiological techniques and molecular characterization of the gene coding for $16 \mathrm{~S}$ ribosomal RNA (16S rRNA) and atr gene by DNA sequencing.

Each step of the procedure (DNA extraction, amplification and detection) was carried out in a distinct area of laboratory with required safeguards for molecular biology tests. All positive results in PCR were retested to assure the positivity.

\section{Molecular Characterization of GBS genomic DNA}

In order to confirm the specificity of GBS atr-primers, purified genomic DNA from S. agalactiae ATCC12403 was amplified by PCR and the amplicon obtained was sequenced by the chain terminators method (Amersham Biosciences ET Terminator Kit) using MegaBACE 1000, following the manufacturer's protocols. The atr gene is a housekeeping gene and its DNA sequence obtained was compared to all known sequences in GenBank using the Basic Local Alignment Search Tool (BLAST) of National Center for Biotechnology Information, Bethesda, MD.

\section{Specificity Assay for the atr-primers}

Purified genomic DNA was obtained from cultures of clinical isolates of Staphylococcus aureus, Staphylococcus epidermidis, Acinetobacter sp., Serratia sp., Salmonella sp., Proteus mirabillis, Citrobacter sp., and Morganella morganii, and submitted to PCR amplification with the atr-primers. Additionally, genomic DNA were obtained from cultures of clinical isolates of Streptococcus pyogenes, Streptococcus uberis, Enterococcus faecalis and Escherichia coli, and mixed with and without $S$. agalactiae DNA. The mixtures were subsequently submitted to PCR amplification with the atrprimers. 


\section{Statistical Analysis}

Sensitivity, specificity, and positive and negative predictive values along with their $95 \%$ confidence intervals were calculated for the combined culture PCR method, using the conventional microbiological method recommended by CDC, as standard. Kappa coefficient was used to evaluate the agreement between the methods (33). The statistical analysis was performed using $\operatorname{SPSS}^{\circledR}$ v.12.

\section{RESULTS}

\section{Specificity of the atr-primers for GBS identification}

In a first approach, the atr-primers were submitted to a primer-BLAST test against all the sequences deposited at GenBank, EMBL, DDBJ and PDB. The results showed just three in silico amplicons, all of them concerning the amino acid ABC transporter ATP-binding protein of S. agalactiae (atr gene) and with the expected 779bp length.

To experimentally evaluate the specificity of atr-primers, 779bp PCR amplicon obtained from S. agalactiae ATCC 12403 was sequenced and compared with the overall information deposited at the GenBank. This amplicon showed a $100 \%$ identity with the S. agalactiae atr sequences, followed by $78 \%$ identity with $S$. suis atr sequences $\left(3 \mathrm{e}^{-117}\right)$.

In order to confirm the specificity of the PCR test in the presence of other bacteria two tests were performed. In the first test, DNA from two species of Streptococcus (S. pyogenes and S. uberis), Enterococcus faecalis, and E. coli, were mixed and submitted to PCR amplification. No amplicons were detected in this sample, but when $S$. agalactiae DNA was included in the mixture the expected amplicon (779bp) was obtained (Figure 1.A).

In a second experiment, DNA from clinical isolates of eight bacterial species currently found in vaginal and rectal samples (S. aureus, S. epidermidis, Acinetobacter sp., Serratia sp., Salmonella sp., P. mirabilis, Citrobacter sp., and $M$. morganii) were submitted to PCR amplification using the atrprimers, showing PCR negative results (Figure 1.B).

These results indicate that the atr-primers designed are highly specific for $S$. agalactiae, and that the presence of other bacterial DNA did not interfere with atr-PCR amplification.
A

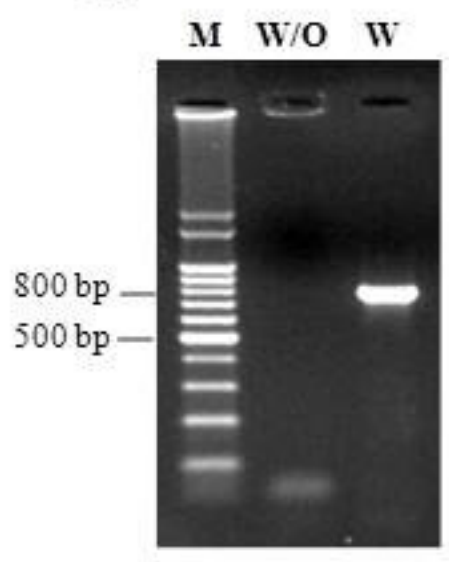

B

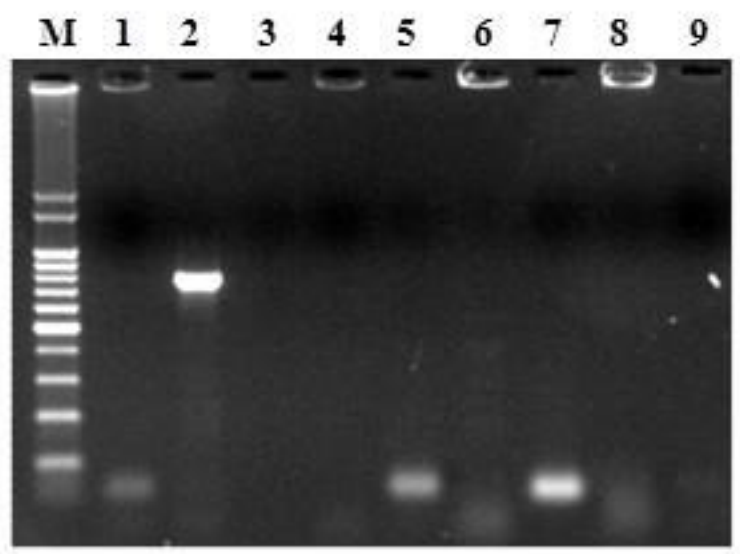

Figure 1. Results for PCR assay with the atr-primers to the mix of DNA with and without S. agalactiae (A) and for the cultures of clinical isolates (B). Lane M- 100-bp molecular-size standard. Lane W/O- mix of DNA without S. agalactiae. Lane W- mix of DNA with S. agalactiae. Lane 1- Proteus mirabillis. Lane 2- S. agalactiae. Lane 3- Staphylococcus aureus. Lane 4Staphylococcus epidermidis. Lane 5- Acinetobacter sp. Lane 6- Serratia sp. Lane 7- Salmonella sp. Lane 8- Morganella morganii. Lane 9- Citrobacter sp. 


\section{Performance of PCR for GBS detection}

A total of 89 pregnant women were screened for GBS colonization using the traditional enrichment/culture method, and the combined enrichment-PCR based procedure (PCR) proposed in this work. A total of 32 patients (35.9\%) were identified as carriers of GBS on the basis of PCR results, as compared with just 20 patients $(22.5 \%)$ on the basis of the traditional enrichment/culture method.

All positive samples according to the culture methods were also positive by the PCR technique, indicating that the sensitivity of the PCR assay was $100 \%$. The highest number of positive samples detected by the PCR method can be attributed to its high accuracy, as it is able to detect as low as 1-2 bacteria per $\mu \mathrm{L}$, been particularly interesting for the diagnosis of asymptomatic and lightly charged GBS patients.

Among the 69 culture-negative samples for GBS, 12 were positive by PCR and 57 were negative in both methods. Considering the culture method as gold standard, the enrichment/PCR method showed a specificity of $82.6 \%$ (Figure 2 ), and positive and negative predictive values of $62.5 \%$ and $100 \%$, for the enrichment/culture and the PCR methods, respectively. Moreover, the index of agreement (Kappa) between the techniques was 0.68. This apparent lower specificity is associated to the higher sensibility of PCR, and not to a lower "specificity" of this technique.

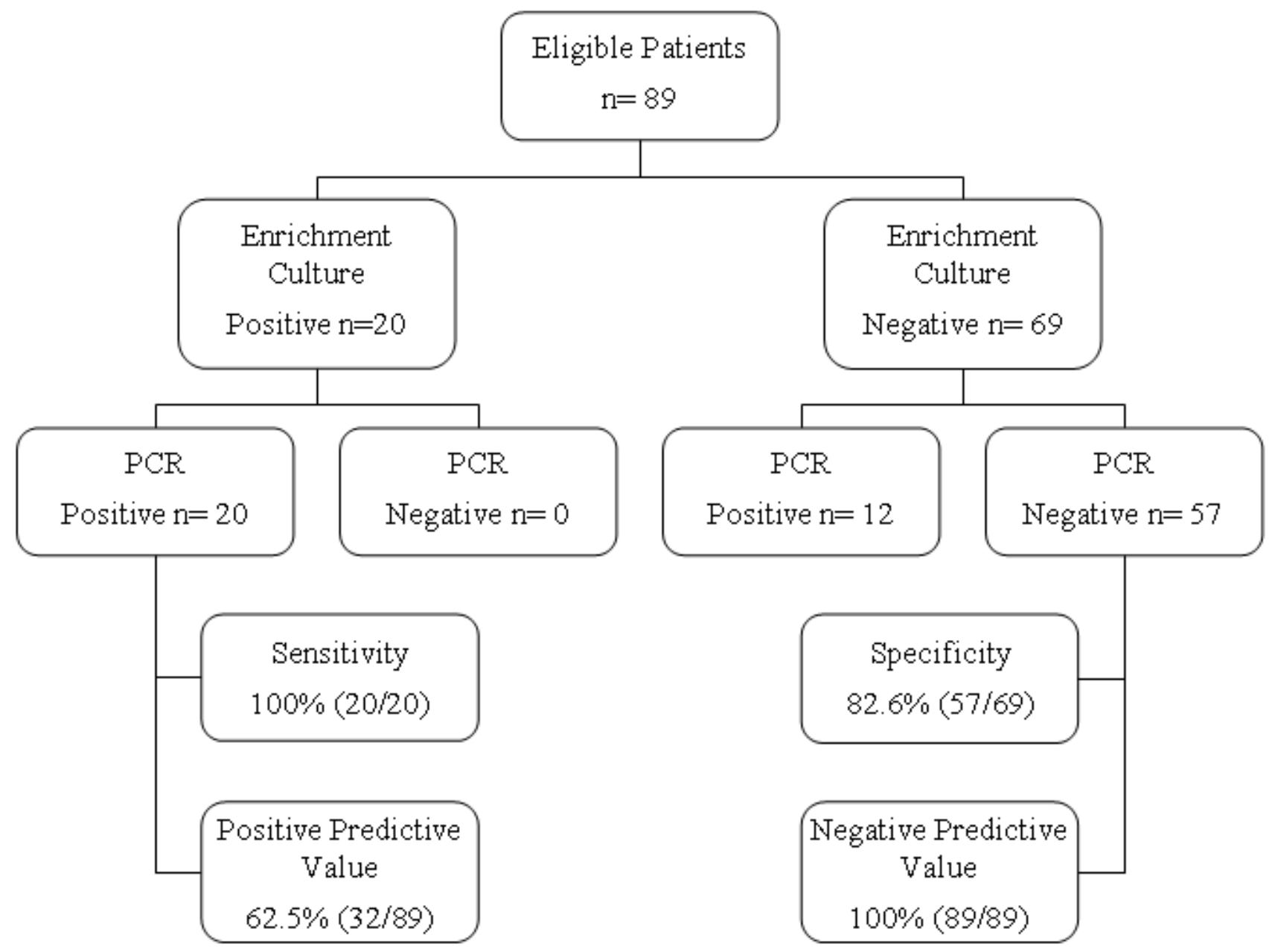

Figure 2. Flow diagram of the diagnostic accuracy study of a PCR assay to identify the presence of GBS in pregnant women. 


\section{DISCUSSION}

The aim of this study was to develop a more accurate and faster screening test for GBS than the standard culture method. We compared two GBS identification screening methods in pregnant women: enrichment culture (as recommended by CDC) (10) and a combined enrichment/PCR method.

Nowadays, as recommended by $\mathrm{CDC}$, the standard method for the diagnosis of GBS in pregnant women consists of vaginal and anal sampling, enrichment in selective broth, and colony identification by routine microbiological methods (10, 19). Alternatively, immunological tests have been developed for GBS detection during labor in an effort to optimize specific intrapartum antibiotic prophylaxis. However, these antigen-based tests are neither sensitive nor specific enough to substitute routine bacterial culture methods, especially in lightly colonized patients $(1,3,5,10,14)$. This is a cause of concern as many infected neonates were born from lightly colonized women, as showed in clinical studies (5).

In the last decade, molecular techniques emerged as alternatives for the rapid and specific diagnostic of several infectious agents including GBS (8, 12). PCR-based approaches for GBS detection include direct amplification or nested-PCR of $16 \mathrm{~S}$ rRNA gene $(18,20,40)$ and amplification using primers specifically designed for the GBS CAMP factor gene $(c f b)$. Although efficient, these approaches are limited by the increased risk of carryover of nested PCR and the absence of CAMP factor in some GBS isolates. To overcome these problems, in the present study, we used species specific primers that amplified part of the housekeeping atr gene of GBS.

Experimental data showed that the use of atr-primers for GBS screening resulted in a high sensitivity (100\%) when compared with the values obtained by PCR amplification with other primers $(8,12,27,30)$. The PCR approach showed a specificity of just $82.6 \%$ in relation with the conventional culture method. However, the low specificity should be regard carefully as the formulae adopted considered the culture method as gold standard, but experimental data have shown that the conventional culture procedures are not sensitive enough to detect GBS in low charge samples. In fact, the lower specificity of PCR is due to its ability to detect GBS in samples where the culture method failed. When amplifications are performed after a short term culture of the specimens into selective enrichment broth, the atr-primers showed high analytical specificity for GBS. The prevalence of positive results for GBS detection was considerable higher when assessed by the combined enrichment/PCR method than with the enrichment culture (35.9\% versus $22.5 \%$, respectively).

The prevalence of $35,9 \%$ found in this work for GBS among pregnant women using the enrichment culture/PCR method is higher than previous results obtained in Brazil which varied between $15 \%$ and $26 \%(6,7,11,22,26,35)$. This difference can be attributed to the highest sensibility of the method adopted in the present study. This enrichment/PCR method integrates high specificity, sensibility and allows the detection of GBS even in lightly colonized patients. Moreover, the amplicons obtained with the selected primers can be also used to perform epidemiologic studies by MLST approach. Considering the newborn contamination risk imposed by lightly colonized mothers, the high sensibility of PCR based approaches, in particular the proposed enrichment/PCR method, may contribute to the proper prophylaxis and consequent reduction of the neonate infectious diseases caused by GBS.

In addition to its accuracy, the enrichment/PCR method is performed in a moderate time (24-36 hours) when compared to standard culture-based methods (48-72 hours), allowing to adopt the prophylactic protocols earlier and with better results. Moreover, the swabs can be analyzed by the combined enrichment/PCR method until 15 days after samples collection (data not shown), without any reduction in the accuracy. This fact may allow the screening of pregnant women from remote areas where there are not laboratory facilities. 
In conclusion, the results demonstrated that the use of selective enrichment broth followed by PCR targeting the atr gene is an excellent test for GBS screening in pregnant women. This PCR methodology may provide a diagnostic tool for GBS detection, potentially allowing more accurate and effective intrapartum antibiotic prophylaxis and lower newborn mortality and morbidity.

\section{ACKNOWLEDGEMENTS}

This study was supported by grants from Conselho Nacional de Desenvolvimento Científico e Tecnológico (CNPq), Fundação de Amparo à Pesquisa do Estado do Rio Grande do Sul (FAPERGS) and Hospital de Clínicas de Porto Alegre (HCPA).

\section{REFERENCES}

1. Adler, A.; Block, C.; Engelstein, D.; Hochner-Celnikcier, D.; DraiHassid, R.; Moses, A.E. (2008). Culture-based methods for detection and identification of Streptococcus agalactiae in pregnant women-what are we missing? Eur J Clin Microbiol Infec Dis. 27 (3), 241-243.

2. Alsoub, H.; Najma, F.; Robida, A. (1997). Group B streptococcal endocarditis in children beyond the neonatal period. Pediatr Infect Dis J. 16 (4), 418-420.

3. American College of Obstetricians and Gynecologists. (2002) Committee Opinion: number 279, December 2002. Prevention of early-onset group B streptococcal disease in newborns. Obstet Gynecol. 100 (6), 14051412 .

4. Baker, C.J.; Clark, D.J.; Barrett, F.F. (1973). Selective broth medium for isolation of group B streptococci. Appl Microbiol. 26 (6), 884-885.

5. Baker, C.J. (1973). Inadequacy of rapid immunoassays for intrapartum detection of group B streptococcal carriers. Obstet Gynecol. 88 (1), 5155.

6. Benchetrit, L.C.; Fracalanzza, S.E.L.; Peregrino, H.; Camelo, A.A.; Sanches, L.A.L.R. (1982). Carriage of Streptococcus agalactiae in women and neonates and distribution of serological types: a study in Brazil. J Clin Microbiol. 15 (5), 787-790.

7. Beraldo, C.; Brito, A.S.J.; Saridakis, H.O.; Matsuo, T. (2004). Prevalência da colonização vaginal e anorretal por estreptococo do grupo B em gestantes do terceiro trimestre. Rev Bras Ginecol Obstet. 26 (7), 543-549.
8. Bergeron, M.G.; Ke, D.; Menard, C.; Picard, F.J.; Gagnon, M.; Bernier, M.; Ouellette, M.; Roy, P.H.; Marcoux, S.; Fraser, W.D. (2000). Rapid detection of group B streptococci in pregnant women at delivery. $N$ Engl J Med. 343 (3), 175-179.

9. Bossuyt, P.M.; Reitsma, J.B.; Bruns, D.E.; Gatsomis, C.A.; Glasziou, P.P.; Irwig, L.M.; Lijmer, J.G.; Moher, D.; Rennie, D.; de Vet, H.C.W. (2003). Towards complete and accurate reporting of studies of diagnostic accuracy: the STARD initiative. Clin Chem. 49 (1), 1-6

10. Centers for Disease Control and Prevention. (2002). Prevention of perinatal group B streptococcal disease. Revised guidelines from CDC. MMWR CDC Surveill Summ. 51 (RR11), 1-22.

11. Costa, A.L.R.; Filho, F.L.; Chein, M.B.C.; Brito, L.M.O.; Lamy, Z.C.; Andrade, K.L. (2008). Prevalence of colonization by group B Streptococcus in pregnant women from a public maternity of Northwest region of Brazil. Rev Bras Ginecol Obstet. 30 (6), 274-280.

12. Davies, H.D.; Miller, M.; Faro, S.; Gregson, D.; Kehl, S.; Jordan, J. (2004). Multicenter study of a rapid molecular-based assay for the diagnosis of group B streptococcus colonization in pregnant women. Clin Infect Dis. 39 (8), 1129-1135.

13. Gardner, S.E.; Yow, M.D.; Leeds, L.J.; Thompson, P.K.; Mason, E.O.Jr.; Clark, D.J. (1979). Failure of penicillin to eradicate group B streptococcal colonization in the pregnant woman. A couple study. Am J Obstet Gynecol. 135 (8), 1062-1065.

14. Hall, R.T.; Barnes, W.; Krishnan, L.; Harris, D.J.; Rhodes, P.G.; Fayez, J.; Miller, G.L. (1976). Antibiotic treatment of parturient women colonized with group B streptococci. Am J Obstet Gynecol. 124 (6), 630634.

15. Heelan, J.S.; Struminsky, J.; Lauro, P.; Sung, C.J. (2005). Evaluation of a new selective enrichment broth for detection of group B streptococci in pregnant women. J Clin Microbiol. 43 (2), 896-897.

16. Jolley, K. A.; Chan, M.; Maiden, M. C. J. (2004). mlstdbNet distributed multi-locus sequence typing (MLST) databases. BMC Bioinformatics, 5:86. http://www.ncbi.nlm.nih.gov/pmc/articles/PMC459212/

17. Jones, N.; Bohnsack, J.F.; Takahashi, S.; Oliver, K.A.; Chan, M.S.; Kunst, F.; Glaser, P.; Rusniok, C.; Crook, D.W.; Harding, R.M.; Bisharat, N.; Spratt, B.G. (2003). Multilocus sequence typing system for group B streptococcus. J Clin Microbiol. 41 (6), 2530-2536.

18. Ke, D.; Ménard, C.; Picard, F.; Boissinot, M.; Ouellette, M.; Roy, P.; Bergeron, M. (2000). Development of conventional and real-time PCR assay for the rapid detection of group B streptococci. Clin Chem. 46 (3), 324-331.

19. Larsen, J.W.; Sever, J.L. (2008). Group B Streptococcus and pregnancy: a review. Am J Obstet Gynecol. 198 (4), 440-450.

20. Martinez, G.; Harel, J.; Gottschalk, M. (2001). Specific detection by PCR of Streptococcus agalactiae in milk. Can J Vet Res. 65 (1), 68-72. 
21. Miura, E.; Martin, M.C. (2001). Group B streptococcal neonatal infections in Rio Grande do Sul, Brazil. Rev Inst Med Trop São Paulo. 43 (5), 243-246.

22. Mocelin, C.O.; Carvalho, D.A.F.; Brites, C.; Christofolli, D.; Mocelin, A.O.; Fracalanzza, S.E.L.; Longo, S.E.; Saridakis, H.O. (1995). Isolamento do Streptococcus agalactiae de gestantes na região de Londrina-PR. Rev Bras Ginecol Obstet. 17 (9), 915-918.

23. Nomura, M.L.; Passini Júnior, R.; Oliveira, U.M. (2005). Group B streptococcus colonization in preterm labor and preterm premature rupture of membranes. Int J Gynaecol Obstet. 91 (1), 69-70

24. Phares, C.R.; Lynfield, R.; Farley, M.M. (2008). Epidemiology of invasive group B streptococcal disease in the United States, $1999-2005$. JAMA. 299 (17), 2056-2065.

25. Pinheiro, R.S.; Ferreira, L.C.L.; Brun, I.R.; Guilherme, J.P.; Monte, R.L. (2007). Estudo dos fatores de risco maternos associados à sepse neonatal precoce em hospital terciário da Amazônia brasileira. Rev Bras Ginecol Obstet. 29 (8), 387-95.

26. Pogere, A.; Zoccoli, C.M.; Tobouti, N.R.; Freitas, P.F.; d'Acampora, J.; Zunino, J.N. (2005). Prevalência da colonização pelo estreptococo do grupo B em gestantes atendidas no ambulatório de pré-natal. Rev Bras Ginecol Obstet. 27 (4), 174-180.

27. Rallu, F.; Barriga, P.; Scrivo, C.; Martel-Laferrière, V.; Laferrière, C. (2006). Sensitivities of antigen detection and PCR assays greatly increased compared to that of the standard culture method for screening for group B streptococcus carriage in pregnant women. J Clin Microbiol. 44 (3), 725-728.

28. Regan, J.A.; Klebanoff, M.A.; Nugent, R.P. (1991). The epidemiology of group B streptococcal colonization in pregnancy. Vaginal Infections and Prematurity Study Group. Obstet Gynecol. 77 (4), 604-610.

29. Schrag, S.J.; Zell, E.R.; Lynfield, R.; Roome, A.; Arnold, K.E.; Craig, A.S.; Harrison, L.H.; Reingold, A.; Stefonek, K.; Smith, G.; Gamble, M.; Schuchat, A. (2002). A population-based comparison of strategies to prevent early-onset group B streptococcal disease in neonates. NEJM.
347 (4), 233-239.

30. Schrag, S.J. (2004). The past and future of perinatal group B streptococcal disease prevention. Clin Infect Dis. 39 (8), 1136-1188.

31. Schuchat, A. (1998). Epidemiology of group B streptococcal disease in the United States: shifting paradigms. Clin Microbiol Rev. 11 (3), $497-$ 513.

32. Schwartz, B.; Schuchat, A.; Oxtoby, M.J.; Cochi, S.L.; Hightower, A.; Broome, C.V. (1991). Invasive group B streptococcal disease in adults. A population-based study in metropolitan Atlanta. JAMA. 266 (8), 11121114.

33. Sim, J.; Wright, C.C. (2005). The Kappa Statistic in Reliability Studies: Use, Interpretation, and Sample Size Requirements. Physical Therapy. 85 (3), 257-268.

34. Sledge, D.; Austin, E.; Sobczyk, W.; Rabalais, G. (1994). Group B streptococcal endocarditis involving the tricuspid valve in a 7-month-old infant. Clin Infect Dis. 19 (1), 166-168.

35. Smânia-Júnior, A.; Benchetrit, L.C.; Smânia, E.F.A.; Fracalanzza, S.E.L. (1986). Isolamento do estreptococos do grupo B de gestantes e neonatos em Florianópolis, Santa Catarina. Rev Bras Anal Clin. 18 (4), 103-108.

36. Streptococcus agalactiae Multi Locus Sequence Typing (MLST) website. Available at: http://pubmlst.org/sagalactiae/. Accessed 26 June 2011.

37. Winn, H.N. (2007). Group B streptococcus infection in pregnancy. Clin Perinatol. 34 (3), 387-392.

38. Young, N.; Finn, A.; Powell, C. (1996). Group B Streptococcal epiglottitis. Pediatr Infect Dis J. 15 (1), 95-96.

39. Yu-Ping, J.; Dong-Shun, Z.; Hong-Kun, Z.; Ren-Zhong, W.; Wen-Qiang, L.; Jing-Dong, H. (2006). A nested PCR-based method for detection of Streptococcus agalactiae 16S rRNA in milk and its application. Chin J Agric Biotechn. 3 (2), 115-118.

40. Zangwill, K.M.; Schuchat, A.; Wenger, J.D. (1992). Group B streptococcal disease in the United States, 1990, report from a multistate active surveillance system. MMWR CDC Surveill Summ. 41 (6), 25-32. 